\title{
Surface Roughness Characterization of Inconel 718 after Laser Assisted Turning
}

\author{
Agata Felusiak $^{1, a}$, Tadeusz Chwalczuk ${ }^{1}$ and Martyna Wiciak ${ }^{1}$ \\ ${ }^{1}$ Poznan University of Technology, Piotrowo 3 St., 60-965 Poznan, Poland
}

\begin{abstract}
This paper describes the surface roughness parameters evaluation of Inconel 718 (43 HRC) after turning under laser assisted conditions. The experiment was conducted for cemented carbides inserts under various cutting and laser heating parameters. Tesets based on central composite research program allows to describe an interaction between input (cutting speed $v_{c}$, laser power $P$, feed $f$ ) and output (roughness parameters according to PN-ISO 4288: $R a, R z, R t, R s k, R S m, R d q$ ) parameters. The results showed that laser power density decrease values of amplitude type of roughness parameters. Such occurrence is not observed for horizonal and hybrid parameters of surface. The function is not described by monotonic projection. Therefore optimization by usability function was performed to observe complex interaction between input and output values. The findings of this work define which one of values from cutting speed, laser power and feed values have crucial impact on surface roughness constitution.
\end{abstract}

\section{Introduction}

Inconel 718 is one of the most frequently applied nickel-based superalloy. The reason of this are, among others, strength and anti-corrosive properties at high temperatures [1]. Another important feature is higher amount of iron which significantly decreases the cost of material. However, high amount of iron lowers the work temperature of the 718 alloy. Mass fractions of elements in Inconel 718 are given in Table 1.

Table 1. Chemical composition of Inconel 718 alloy (weight \%).

\begin{tabular}{|c|c|c|c|c|c|c|c|c|c|c|c|c|c|c|}
\hline $\mathbf{N i}$ & $\mathbf{C r}$ & $\mathbf{N b}$ & $\mathbf{M o}$ & $\mathbf{T i}$ & $\mathbf{A l}$ & $\mathbf{C o}$ & $\mathbf{S i}$ & $\mathbf{M n}$ & $\mathbf{C u}$ & $\mathbf{C}$ & $\mathbf{P}$ & $\mathbf{S}$ & $\mathbf{B}$ & $\mathbf{F e}$ \\
\hline $50,00-$ & $17,00-$ & $4,75-$ & $2,80-$ & $0,65-$ & $0,20-$ & $\max$ & $\max$ & $\max$ & $\max$ & $\max$ & $\max$ & $\max$ & $\max$ & \\
55,00 & 21,00 & 5,50 & 3,30 & 1,15 & 0,80 & 1,00 & 0,35 & 0,35 & 0,30 & 0,08 & 0,015 & 0,015 & 0,006 & balance \\
\hline
\end{tabular}

Nickel-based superalloys are mainly applied in aviation and marine industry as parts of gas turbines, space shuttles and nuclear reactors. They are characterized by a great durability at high temperatures, wear and corrosion resistance, and a superior creep resistance below $700^{\circ} \mathrm{C}[2,3]$.

\footnotetext{
${ }^{a}$ Corresponding author : agata.z.felusiak@doctorate.put.poznan.pl
} 
Alloys of Inconel group, including 718 alloy, are considered to be hard-to-cut materials. It is related with work-hardening and high temperature occurring in the cutting zone which eventually results in accelerated tool wear. Inconel exhibits strong affinity for formation of adhesive bonds with the cutting edge. This results in creation built-ups on the flank face and the rake face. Moreover, this is the reason of the side material flow. According to the research [4], roughness of machined surface is mainly influenced by the initiation of plastic chip side flow, equal progress of tool wear and formation of built-up on the cutting edge.

In relation to difficult machining of 718 alloy, researchers are searching for new methods to make this process easier. Another trouble is maintaining low roughness of obtained surfaces which is a common requirement for parts made of nickel-based superalloys [5]. One of the methods is application of high speed machining (HSM). It was proved in researches [6] that usage of cutting speed equal to approximately $190 \mathrm{~m} / \mathrm{min}$ leads to a lowering of roughness with insignificant increase of tool wear, in comparison with the usage of lower cutting speeds. However, application of higher cutting speed shorten the tool life significantly and worsen the condition of machined surface.

Another method which leads to improve machinability of nickel-based superalloys, including Inconel 718, is application of laser assisted machining (LAM) [7, 8]. The usage of LAM is based on heating the workpiece with laser beam of high power in order to soften the material which results in decreasing cutting forces and durability of workpiece during machining [9, 10]. As the researches show $[11,12]$, the usage of laser assist improve the quality of machined surface- approximately 3times decrease in roughness was noted. Furthermore, in comparison with conventional machining, longer tool life was spotted.

\section{Experimental details}

\subsection{Applied process technology}

In this research shaft made of Inconel 718 was machined. For the machining process, cemented carbide WNMG 080408EN inserts produced by CERATIZIT were used and they were attached with MNLNL2020 K08 tool-holder. The research was carried out on a numerically controlled CTX310 Ecoline lathe with self-centric hydraulic three-jaw chuck. For laser assisted machining, diode laser TRUMPF TruDiode 3004 was applied. Machining was carried out in accordance with the scheme shown in Figure 1. The treatment was carried out in accordance to the research plan given in Table 2. Depth of cut and laser spot diameter were constant and equal to respectively $a_{p}=0,15 \mathrm{~mm}$ and $d_{l}=1 \mathrm{~mm}$. Variable laser beam power and its constant geometry result in variable surface laser beam power density. In this research, machining with simultaneously heating using laser beam was applied.

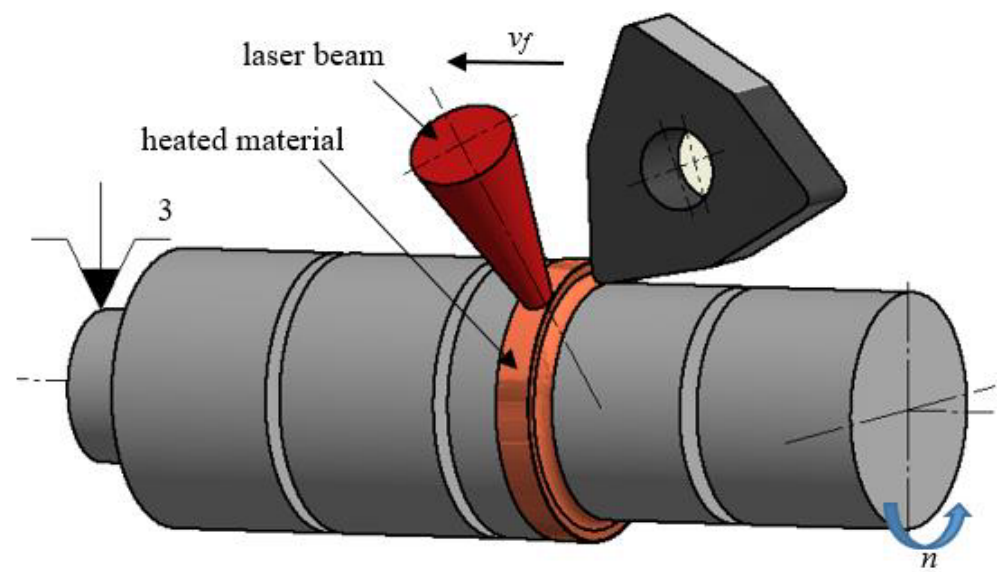

Figure 1. The scheme of machining with laser assistant. 
Table 2. Applied plan of research.

\begin{tabular}{|r|c|c|c|c|c|c|}
\cline { 2 - 7 } \multicolumn{1}{c|}{} & \multicolumn{3}{c|}{ CODED VALUE } & \multicolumn{3}{c|}{ REAL VALUE } \\
\hline \multirow{2}{*}{$\mathrm{nr}$} & $v_{c}$ & $f$ & $P$ & $v_{c}$ & $f$ & $P$ \\
\cline { 2 - 7 } & {$[-]$} & {$[-]$} & {$[-]$} & {$[\mathrm{m} / \mathrm{min}]$} & {$[\mathrm{mm} / \mathrm{rev}]$} & {$[\mathrm{W}]$} \\
\hline 1 & $-1,682$ & 0,000 & 0,000 & 20 & 0,100 & 1400 \\
\hline 2 & $-1,000$ & $-1,000$ & $-1,000$ & 32 & 0,073 & 1162 \\
\hline 3 & $-1,000$ & $-1,000$ & 1,000 & 32 & 0,073 & 1638 \\
\hline 4 & $-1,000$ & 1,000 & $-1,000$ & 32 & 0,127 & 1162 \\
\hline 5 & $-1,000$ & 1,000 & 1,000 & 32 & 0,127 & 1638 \\
\hline 6 & 0,000 & $-1,682$ & 0,000 & 50 & 0,055 & 1400 \\
\hline 7 & 0,000 & 0,000 & $-1,682$ & 50 & 0,100 & 1000 \\
\hline 8 & 0,000 & 0,000 & 0,000 & 50 & 0,100 & 1400 \\
\hline 9 & 0,000 & 0,000 & 0,000 & 50 & 0,100 & 1400 \\
\hline 10 & 0.000 & 0,000 & 1,682 & 50 & 0,100 & 1800 \\
\hline 11 & 0,000 & 1,682 & 0,000 & 50 & 0,145 & 1400 \\
\hline 12 & 1,000 & $-1,000$ & $-1,000$ & 68 & 0,073 & 1162 \\
\hline 13 & 1,000 & $-1,000$ & 1,000 & 68 & 0,073 & 1638 \\
\hline 14 & 1,000 & 1,000 & $-1,000$ & 68 & 0,127 & 1162 \\
\hline 15 & 1,000 & 1,000 & 1,000 & 68 & 0,127 & 1638 \\
\hline 16 & 1,682 & 0,000 & 0,000 & 80 & 0,100 & 1400 \\
\hline
\end{tabular}

\subsection{Carried out measurements}

For each parameters set from Table 2 five roughness measurements were taken. For the surface topography assessment, stationary profilographometer T8000 was carried out. Measuring length used was equal to $l n=4 \mathrm{~mm}$ and elementary section was $l r=0,08 \mathrm{~mm}$ according to the PN-ISO 4288:1998 standard. Basing on obtained surfaces' profiles following roughness parameters were calculated: $R a$, $R z, R t, R s k, R q, R S m, R d q$.

\section{Results and discussion}

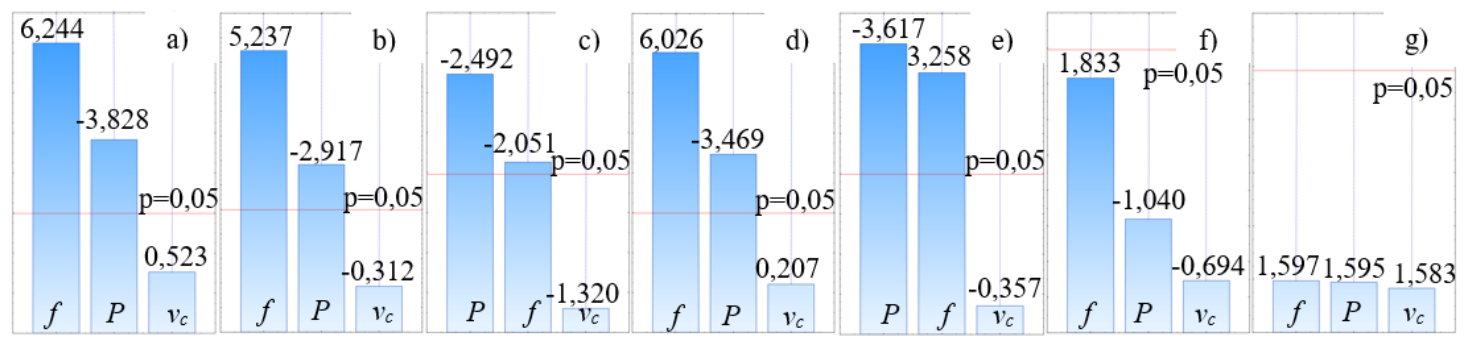

Figure 2. Pareto chart of effects of input parameters influence on roughness parameters: a) $R a$, b) $R z$, c) $R s k$, d) $R q$, e) $R t$, f) $R S m$, g) $R d q$.

In Figure 2 the significance of impact of different variables on obtained roughness parameters. As it results from carried out Pareto analysis of effects for confidence interval equal to $p=0,05$, roughness is most significantly influenced by feed rate and laser beam power, whereby the feed rate mainly 
influences two most commonly considered parameters: $R a$ and $R z$. It is seen that the cutting speed has no influence on surface roughness in the preset range of cutting parameters. Moreover, no influence of feed rate on the average offset between profile's peaks $(R S m)$ which theoretically should be approximately equal to the feed rate value. In this case the occurrence of material side flow is possible and this phenomenon may have the prevailing impact on the frequency of the profile's peaks formation $(R S m)$. Also the initial state of cutting edge, wear and cutting edge nickness which is reflected on the machined surface, have significance for this roughness parameter. None of the examined parameters have no impact on roughness parameters which describe the tilt of the profile. Feed rate and laser beam power are mostly responsible for surface roughness, however, in further research additional parameters, ex. tool geometry, should be taken into consideration.

The relation of influence of laser beam power and feed rate on values of roughness parameters: average square profile deviation $(R q)$ and the tilt of the profile $(R s k)$ are shown in Figures $3 \mathrm{a}$ and $3 \mathrm{~b}$ respectively.

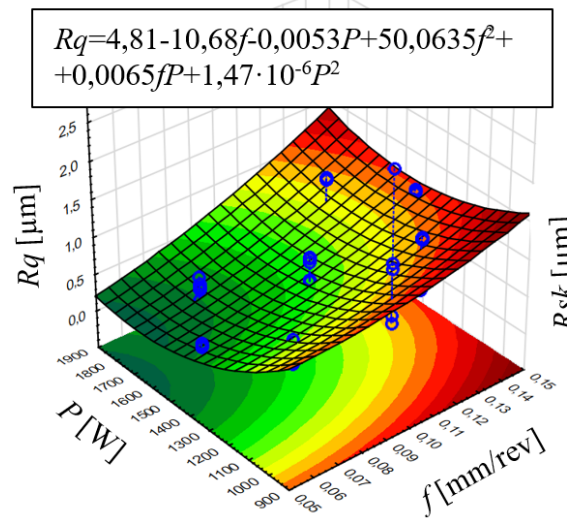

(a)

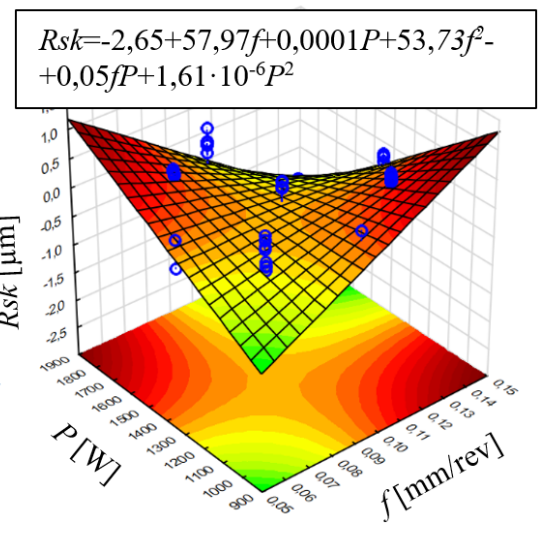

(b)

Figure 3. Laser power and feed influence on value: a) $R q$, b) $R s k$.

During the analysis of the impact of laser beam power and feed rate on roughness parameters it was spotted that the roughness increases with increasing the value of feed and decreases with increasing the laser beam power, primarily for low feed rates. An exception to this phenomenon is only the tilt of the profile $(R s k)$. In this diagram, there is no clear relation between laser beam power and feed and this relation depends on combination of these two parameters. Remaining parameters confirm results described in literature, so decreasing the roughness. For analysis of 3-dimensional diagrams only parameters for which, according to Pareto chart, the significance for the confidence interval equal to $p=0,05$ occurred.

In Figure 4 compares the theoretical and the measured values roughness parameter $R z$. Values of roughness obtained from regression model of two variables differ significantly from theoretical value. The theoretical value of roughness parameter $R z$ was calculated for arc projection according to the Formula 1:

where:

$$
R z_{t}=\frac{f^{2}}{8 r_{\varepsilon}}
$$

$f$ - feed $[\mathrm{mm} / \mathrm{rev}]$

$r_{\varepsilon}-$ insert nose radius $[\mathrm{mm}]$.

The higher laser beam power (to $1400 \mathrm{~W}$ ), the values are closer to the theoretical one, due to among others reduction of surface hardening. The rapid increase of roughness is related to too deep heating in comparison with the depth of cut which causes modification of materials' ductility and results in heightening maximal peaks of profile due to plastic deformation of the workpiece. Differences in theoretical and measured values derive from not taking into consideration some phenomena, ex. elastic-plastic deformations and vibrations [13]. 


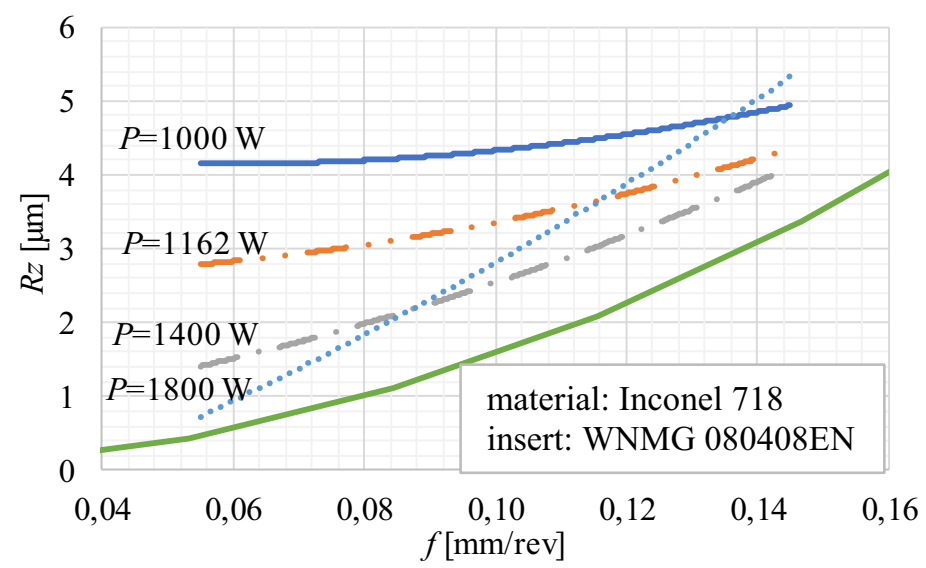

Figure 4. Theoretical surface roughness $R z_{t}$ roughness measured after laser assistant turning Inconel 718 .

Profiles of usability of examined parameters are shown in Figure 5 with simultaneously multicriteria optimization. Nevertheless, with increasing the laser beam power the value of average arithmetical profile deviation, due to simultaneously consideration of two roughness parameters $(R a$ and $R s k$ ), the highest usability is obtained for medium laser beam power. Variable cutting speed, in combination with other parameters, influences the distribution of $R s k$ parameter. It is significant that the impact of cutting speed itself is reduced by other parameters which results from aforementioned Pareto charts. However, the comparison of parameters of lowest usability will worsen the roughness of machined surface even more than it results only from single-criteria analysis. For extremal values of cutting speed, Rsk values become negative which is not typical for turning because the roughness profile character changes from peak to valley.

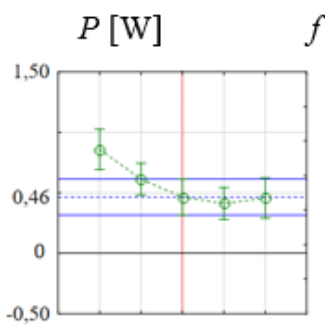

$f[\mathrm{~mm} / \mathrm{rev}]$
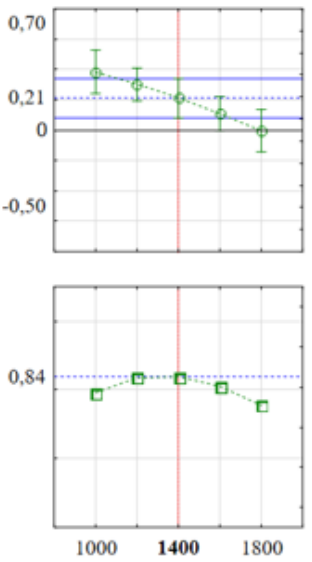
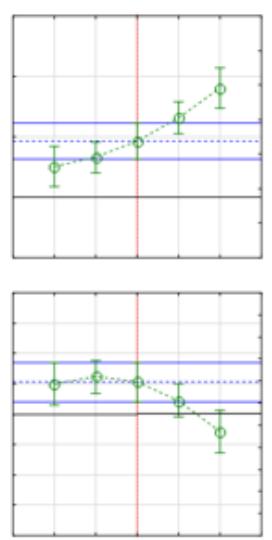

$v_{c}[\mathrm{~m} / \mathrm{min}]$
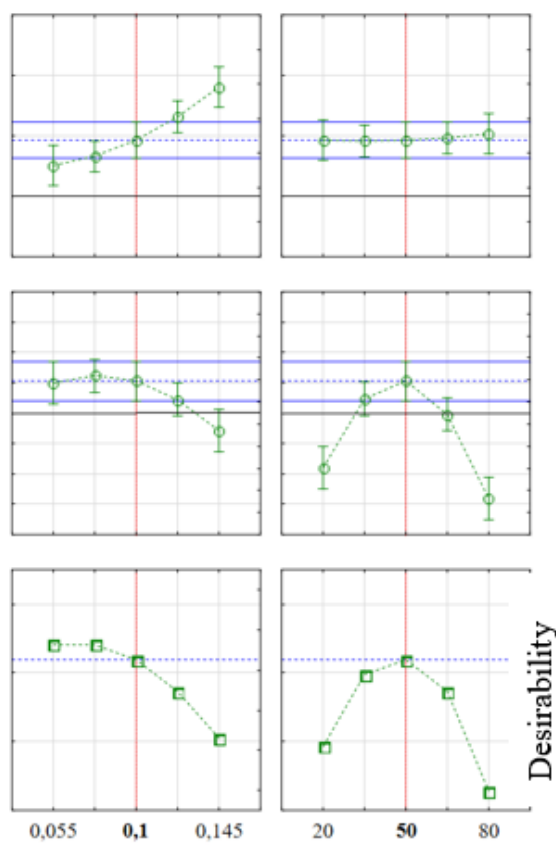

\section{Desirability}
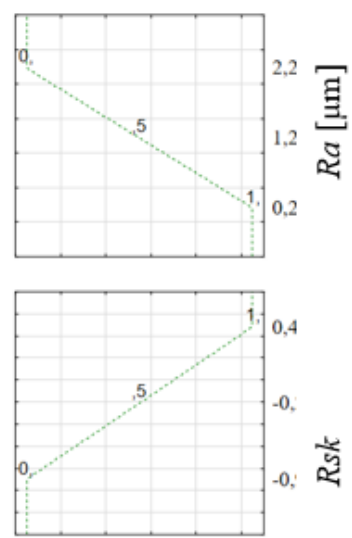

Figure 5. Results of usability function analysis. 


\section{Conclusion}

On the basis of conducted research following conclusions were formulated:

- Increase of laser beam power allows to obtain lower values of machined surface roughness parameters. The significant restriction is the depth of workpiece heat softening.

- For low feed rates higher laser beam power can be applied $(P=1800 \mathrm{~W})$ because roughness is convenient if low feed rate is applied. It results from low plastic deformation. This applies until the yield point is exceeded.

- In terms of roughness, the most effective feed rate is ranged between $f=0,055 \mathrm{~mm} / \mathrm{rev}$ and $f=0,073 \mathrm{~mm} / \mathrm{rev}$, the most optimal laser beam power is equal to $P=1400 \mathrm{~W}$ and cutting speed $v_{c}=50$ $\mathrm{m} / \mathrm{min}$.

\section{Acknowledgments}

The presented research results, executed under the domestic project LIDER of No. 164/L6/14/NCBR/2015 with grants for education allocated by the National Centre for Research and Development.

\section{References}

1. W. Grzesik, P. Niesłony, W. Habrat, J. Sieniawski, P. Laskowski, Tribology International 118, 337 (2018)

2. D. Ulutan, T. Özel, International Journal of Machine Tools and Manufacture 51, 250 (2004)

3. P. Kieruj, D. Przestacki, T. Chwalczuk, Archives of Mechanical Technology and Materials 36, 30 (2017)

4. A.Thakur, S.Gangopadhyay, International Journal of Machine Tools and Manufacture 100, 25 (2016)

5. T. Chwalczuk, P. Twardowski, P. Kieruj, P. Szablewski, Zeszyty Naukowe Politechniki Rzeszowskiej 295, 307 (2017)

6. D.M., D'Addona, S.J. Raykar, M.M. Narke, Procedia CIRP 62, 269 (2017)

7. D. Przestacki, T. Chwalczuk, MATEC Web of Conferences, 136 (2017)

8. D. Przestacki, M. Kukliński, A. Bartkowska, International Journal of Advanced Manufacturing Technology 93, 3111 (2017)

9. D. Przestacki, T. Chwalczuk, S. Wojciechowski, International Jiurnal of Advanced Manufacturing Technology 91, 3887 (2017)

10. S. Wojciechowski, D. Przestacki, T. Chwalczuk, MATEC Web of Conferences, 136 (2017)

11. D. Przestacki, M. Jankowiak, Journal of Physics: Conference Series 483 (2014)

12. M. Anderson, R. Patwa, Y.C. Shin, International Journal of Machine Tools and Manufacture 46, 1879 (2006)

13. T. Chwalczuk, M. Rybicki, D. Korzeniewski, D. Przestacki, Mechanik 10, 1312 (2016) 